\title{
Laisser aller e respeito agonístico: considerações sobre as apropriações agonísticas da filosofia de Nietzsche I
}

Jean Gabriel Castro da Costa

\section{Resumo}

Neste artigo, analisamos o uso que os teóricos agonísticos da democracia tem feito da filosofia de Nietzsche com foco em uma de suas principais proposições normativas: a ideia de "respeito agonístico". Na primeira seção, apresentamos características gerais da apropriação da filosofia de Nietzsche pelos teóricos agonísticos da democracia. Na segunda seção, apresentamos o que William Connolly e Lawrence Hatab entendem por "respeito agonístico" e "respeito democrático". Na terceira seção, criticamos estas apropriações da filosofia de Nietzsche a partir de textos do próprio Nietzsche, apontando alguns limites da noção de respeito agonístico e sustentando que estes teóricos utilizam Nietzsche para promover uma ética do laisser aller que foi duramente criticada por ele.

Palavras-chave: Nietzsche. Agonismo. Democracia. Respeito Agonístico.

I Este artigo é um dos frutos da pesquisa realizada durante o meu Estágio Pós-doutoral realizado em 2015-2016 na Brown University, Providence, EUA, e no Graduate Center da City University of New York, Nova lorque, EUA. Agradeço à Coordenação de Aperfeiçoamento de Pessoal de Nível Superior (CAPES) pela bolsa concedida durante o Estágio Pós-doutoral (Processo 99999.005959/2015-02) e aos pareceristas anônimos que avaliaram este artigo.

2 Professor do Departamento de Sociologia e Ciência Política da Universidade Federal de Santa Catarina (UFSC), Florianópolis/SC, Brasil. Pesquisador do Núcleo de Estudos do Pensamento Político (NEPP-UFSC) e do Grupo de Estudos Nietzsche e a Teoria Política (GENTP). E-mail: jeancastrocosta@gmail.com

\section{$(\mathrm{cc}) \mathrm{Br}$}

Direito autoral e licença de uso: Este artigo está licenciado sob uma Licença Creative Commons. Com essa licença você pode compartilhar, adaptar, para qualquer fim, desde que atribua a autoria da obra, forneça um link para a licença, e indicar se foram feitas alterações. 


\section{Características gerais da reflexão dos "teóricos agonísticos da democracia” e de sua apropriação da filosofia de Nietzsche}

O termo "agonismo" é derivado do termo grego "agon", que pode ser traduzido como disputa ou conflito. "Agonismo" era a valorização positiva da disputa na cultura dos gregos antigos. Recentemente, o "agonismo" tem sido objeto de reflexão dos chamados "teóricos agonísticos da democracia”, cujos trabalhos têm alguma repercussão na teoria política anglófona contemporânea ${ }^{3}$. As fontes a partir das quais estes teóricos chegaram ao tema do "agonismo" encontram-se nos escritos de Nietzsche e de pensadores franceses de meados do século XX, que se apropriaram, de maneira singular, da sua filosofia, tais como Foucault, Lyotard, Deleuze e Derrida ${ }^{4}$.

Nietzsche e os pós-estruturalistas franceses são mobilizados pelos teóricos agonísticos da democracia em favor de uma "democracia radical e plural" que iria além dos limites da democracia liberal/procedimental e das alternativas deliberativas que foram apresentadas a ela. Assim, criticam os fundamentos metafísicos do liberalismo, que não se sustentariam mais em regime de "morte de Deus" (ou "morte do fundamento", como preferem alguns). Para os agonistas, não haveria como demonstrar que a Razão seria capaz de nos fornecer uma ideia de bem que seria derivada diretamente da ordem do Ser. Não haveria, portanto, como fundamentar coisas como "direitos universais" em Deus, na razão ou na natureza. Contra essa expectativa, os teóricos agonísticos afirmam que há sempre um elemento de indecidibilidade nos valores últimos sustentados por cada perspectiva, e, se uma destas perspectivas prevalece, é somente porque venceu uma luta e conquistou uma hegemonia, que é sempre provisória e contingente.

Para os teóricos agonísticos, a concepção liberal de um self centrado e autônomo, que seria capaz de escolher livremente entre os fins dados

3 Destacamos, entre estes “teóricos agonísticos da democracia”, William Connolly, Bonnie Honig, Chantal Mouffe, Lawrence Hatab, James Tully e David Owen. Para uma perspectiva panorâmica e crítica dessa vertente da teoria política contemporânea ver: Wenman, 2013. Neste artigo, quando menciono "teóricos agonísticos", refiro-me a traços comuns a todos estes autores. Apresento esses traços para ajudar na compreensão do objeto específico deste artigo, que é o trabalho de Connolly e Hatab em torno da ideia de respeito agonístico.

4 Sobre a centralidade de Nietzsche para os pós-estruturalistas franceses ver: Marton, 2009 e Schrift, 1995. 
socialmente, seria "metafísica" e insustentável, pois os fins são constitutivos do sujeito. Também a partir de Nietzsche e Foucault, os agonistas entendem o self como sendo ele próprio múltiplo, constituído e atravessado por relaçóes de poder. Com Nietzsche, eles dirão que o "um é múltiplo", é uma "formação de domínio que significa um, mas não é um"s. Todas as "unidades", tais como self, grupos sociais e políticos, Estado, são multiplicidades que se mantêm como unidade porque internamente são formações de domínio que estão em relação externa com formaçóes de domínio diferentes, que são, elas próprias, também múltiplas internamente. Isso significa que toda unidade resulta de uma hegemonia, de uma hierarquia entre forças, que é provisória e contingente.

Para os teóricos agonísticos, o ideal liberal de um Estado secular e neutro em relação a valores foi construído a partir de premissas metafísicas ${ }^{6}$, pois o respeito à igualdade e à autonomia dos sujeitos centrados somente seria possível, na leitura liberal, se o Estado se abstivesse de defender alguma doutrina abrangente de bem (para usar a linguagem de Rawls, que é um dos alvos da crítica dos agonistas). Nesta visão liberal, as ideias mais fortes de bem, tais como as que encontramos nas religióes, deveriam permanecer na esfera privada; afinal, se o Estado assumisse como sua uma destas doutrinas abrangentes de bem, estaria ameaçado o igual direito dos cidadãos escolherem, eles mesmos, suas próprias doutrinas abrangentes. Com a perda de credibilidade dos fundamentos metafísicos, a ideia de neutralidade do Estado liberal passa a ser vista, pelos teóricos agonísticos, como uma estratégia de poder que procura mascarar sua própria vontade de poder através da capa da neutralidade e universalidade, pois o próprio ideal liberal é também apenas uma perspectiva que visa à hegemonia ${ }^{7}$. Tal

5 "Toda unidade é apenas unidade enquanto organização e concerto, não é de outro modo quando uma coletividade humana é uma unidade, portanto, antagonismo da anarquia atomista; com isso, uma formação de domínio, que significa Um, mas não é Um”, conforme Nietzsche - KSA 12.104, 2 [87], outono de 1885- outono de 1886 (apud MÜLLER-LAUTER, 2009, p. 67).

6 Para Connolly (1991, p. 73), “[...] quando John Rawls afirma, por exemplo, que 'em uma democracia constitucional a concepção pública de justiça deve ser, tanto quanto possível, independente das controvérsias filosóficas e doutrinas religiosas', ele não escapa da tradição ontoteológica". O trecho citado por Connolly está em Rawls (1985, p. 223), justamente um texto em que Rawls tenta responder aos seus críticos comunitaristas argumentando que sua concepção seria política e não metafísica.

7 Ver Connolly, 1999. 
disfarce de neutralidade, porém, é visto pelos teóricos agonísticos como pior que um poder que se admite abertamente como poder, pois, ao se esconder, tornaria mais difícil o surgimento de resistências, situação que tenderia a promover uma "normalização" exagerada que sufocaria o pluralismo. Dessa forma, a democracia liberal poderia produzir efeitos contrários aos seus próprios objetivos primeiros.

Apesar destas críticas de inspiração nietzschiana aos fundamentos metafísicos do liberalismo, os teóricos agonísticos náo se apresentam como antiliberais. Provenientes da militância política de esquerda, estes teóricos abandonaram expectativas escatológicas da esquerda marxista, mas não o ideário da revolução democrática dos tempos modernos, que eles pretendem aprofundar. Os teóricos agonísticos são "left liberals" (no sentido que o termo tem nos EUA) e a crítica deles ao liberalismo é, em grande medida, imanente, pois consideram que o liberalismo mainstream, seja em versão deontológica ou na versão pluralista, não realiza os seus próprios ideais de liberdade e igualdade, e, ao mesmo tempo, os teóricos agonísticos querem se colocar a serviço da realização destes ideais ${ }^{8}$. Para tanto, além de procurar desmascarar as neutralizaçóes que consideram terem sido realizadas pelo liberalismo mainstream, procuram trazer à tona "o político", em sua dimensão conflitiva, para ampliar o leque de diferenças a serem reconhecidas e incluídas na vida social democrática. Ao mesmo tempo, porém, cientes dos riscos destrutivos do conflito, apelam a um ethos de respeito agonístico como forma de dar medida aos conflitos.

8 Em Hegemonia e Estratégia Socialista, Laclau e Mouffe (200I, p. xv) escrevem que: “[...] a democracia liberal não é o inimigo a destruir para criar, através da revolução, uma sociedade inteiramente nova. [...] o problema com as democracias liberais 'atualmente existentes' não é com seus valores constitutivos cristalizados em seus princípios de liberdade e igualdade para todos, senão com o sistema de poder que redefine e limita a operação destes valores. Por isso, nosso projeto de uma 'democracia radical e plural' foi concebido como uma etapa no aprofundamento da 'revolução democrática', como a extensão das lutas democráticas por igualdade e liberdade a um número crescentemente amplo de relações sociais". Em Political Theory and Modernity, William Connolly (1988, p. 174) diz que: "Talvez um liberalismo reconstituído e radicalizado seja necessário hoje. Um que chegue ao próprio sujeito em vez de tomá-lo como ponto de partida; um que desafie a hegemonia da expansão econômica, em vez de considerá-la uma pré-condição para a liberdade; um que trate a natureza como um lugar da diferença e da resistência que é essencial para a vida tanto quanto um abrigo e uma fonte de recursos para o uso humano". 


\section{Respeito agonístico}

É frequente em teóricos agonísticos da democracia um apelo ético a alguma forma de autolimitação dos atores políticos como meio para manter o conflito político em um nível não destrutivo. Nesse sentido, Connolly defendeu o "respeito agonístico", Mouffe o "respeito ao pluralismo" e Hatab o "respeito democrático" 9 . Os três se referem fundamentalmente ao mesmo conteúdo normativo: um ethos que possibilita a autolimitação dos atores políticos, permitindo que eles encarem as outras perspectivas políticas concorrentes como diferentes e adversárias e não como inimigas a serem destruídas. Ter respeito agonístico “[...] é se esforçar para converter um antagonismo de identidade em um agonismo da diferença, no qual cada um se opóe ao outro (e às suas crenças pressupostas), mas respeitando o adversário em outro nível, como alguém cujas orientaçóes contingentes também se baseiam em bases epistêmicas incertas" (CONNOLLY, 1991, p. 178). Essa atitude seria fundamental para a democracia, pois, na linguagem de Mouffe, "o propósito da política democrática é transformar antagonismo em agonismo" (MOUFFE, 2005, p. 21). Este objetivo explicitado por Mouffe é compartilhado pelos demais teóricos agonísticos. Entre estes teóricos, Connolly e Hatab recorrem explicitamente a Nietzsche para fundamentar seus posicionamentos normativos. Mouffe, por sua vez, é quem menos cita diretamente Nietzsche ${ }^{10}$; por isso, considerando o objetivo deste artigo, concentraremos nossa atençáo nos trabalhos de Connolly e Hatab.

Connolly (1988) apresentou os vínculos entre sua produção teórica e a filosofia de Nietzsche; escreveu que: "[...] pretende privilegiar uma perspectiva nietzschiana sem endossar todos os pronunciamentos políticos que ele fez" (p. 15), e que essa perspectiva seria "pós-nietzschiana” (p. 171) e "estaria para Nietzsche como Marx esteve para Hegel: em uma relaçáo de dívida agonística” (p. 175). Connolly (1988) segue, em grande medida, a leitura de Nietzsche feita por Foucault e Deleuze, mas pretende ser

9 Conforme Connnolly (1991, p. 166); Mouffe (1999, p. 14) e Hatab (1995, p. 67).

10 Entretanto, de alguma maneira, Nietzsche também exerceu influência nas formulações teóricas de Mouffe, pois os pós-estruturalistas franceses (ou os "nietzschianos de esquerda dos anos 60") figuram entre as referências teóricas dela. 
mais explicitamente normativo e político que eles. Assim, Connolly (1991, p. 190) quer contribuir para a criação de um "politizado nietzschianismo de esquerda” que formule uma teoria política abertamente normativa, algo que era evitado por Foucault e Deleuze.

A partir de Nietzsche, Connolly (1988, p. 153) afirma que "[...] os humanos são incompletos fora da forma social, e qualquer forma social requer uma medida de crueldade para completar os humanos de acordo com suas especificaçóes". Quer dizer, o homem seria um "animal indeterminado" que precisa de formas sociais para viver. Ao mesmo tempo, as formas sociais que constituem as identidades não podem ser plenas e sem conflitos, pois os humanos são singulares e nem todos se "encaixariam" igualmente nestas formas sociais. Ainda assim, estas formas são aplicadas a todos, o que pode provocar sofrimento naqueles que não se encaixam. Haveria, portanto, sempre um elemento "crueldade" (pressão, coerção, exclusôes etc.) em qualquer sociedade.

Seguindo uma ontologia nietzschiana do sujeito, Connolly entende a identidade sempre como uma "unidade" internamente múltipla e em devir, que se constrói em relaçôes diferenciais, de identificação ou oposição e resistência com outras identidades. Também a partir de sua leitura de Nietzsche, Connolly entende a construção das identidades sempre em relação com o "problema do sofrimento" e do ressentimento existencial, pois "[...] seres humanos ressentem a transitoriedade e o sofrimento que define sua condição humana. Essa condição pode ser mais bem tolerada se os humanos conseguem encontrar algum agente que seja responsável pelo sofrimento, um agente que se torne repositório do ressentimento" (CONNOLLY, 1988, p. 153). O ressentimento pode ter múltiplas fontes - entre as quais: a finitude, a diferença e comparação com outros, o desejo de obter algo e a impotência de alcançá-lo etc. O ressentimento tende a promover a busca por "culpados" e pode conduzir ao surgimento de identidades fundamentalistas, que negam radicalmente o outro:

O corcunda inverso é aquele cujo autodesprezo e o desejo de vingança o levam a reduzir todos a uma norma e a punir todos aqueles que resistem muito fortemente. Se ele é heterossexual é homofóbico; se ele é homossexual é também heterofóbico; se ele é bissexual é também monofóbico. Ele é doente pela busca de vingança contra a condição humana. Ele 
tem um "olho grande", através do qual ele observa todos, buscando sinais de alteridade e tem uma "boca grande" da qual receitas para reduzir a diferença para mesmice são constantemente emitidas. (CONNOLLY, 1988, p. 165).

No Ocidente, a partir do judaísmo-cristianismo, teria surgido uma configuração específica de identidade, diferença e responsabilidade que estaria vinculada ao que Nietzsche chamou de "niilismo europeu". A partir dessa leitura, Connolly entende a resposta de Santo Agostinho ao problema do mal como um momento decisivo deste processo. Como se sabe, o problema do mal era: se Deus é onipotente e infinitamente bom, como pode haver mal no mundo? Ou ele não é onipotente ou não é bom, teriam sido respostas possíveis. Mas, para salvar a onipotência e a bondade de Deus, Santo Agostinho responde dizendo que Deus deu livre-arbítrio ao homem, e que este passa a ser culpado pelo mal. Para Connolly, a partir desta resposta agostiniana ao primeiro problema do mal nasce o "segundo problema do mal": "[...] o mal que é derivado da tentativa de estabelecer a segurança da identidade de qualquer indivíduo ou grupo através da definiçáo do outro como mau ou irracional" (CONNOLLY, 1991, p. 8). O sujeito centrado e dotado de livre-arbítrio, para preservar sua conduta e identidade, precisa reprimir sua pluralidade interna de forças e negar a pluralidade nos outros indivíduos. Quanto maior a necessidade de conter essa pluralidade interna mais o sujeito precisará negar o desvio dos outros indivíduos. Portanto, a partir da necessidade de manter a qualquer custo sua própria identidade é que nasceria uma intolerância violenta com o diferente" .

Connolly acompanha Nietzsche na consideração de que é nesta configuração cristã que encontramos a origem das ideias modernas de self, identidade, diferença e responsabilidade, e, neste sentido, o humanismo moderno seria um herdeiro do cristianismo. ${ }^{12}$ Contra os efeitos normaliza-

II Mouffe (2007, p. 8I) também notou esse vínculo entre assegurar a qualquer custo a própria identidade moral e a negação dos outros: "[...] deveríamos nos dar conta de que um mecanismo particularmente perverso está em jogo nessas relações moralistas. Este mecanismo consiste em assegurar a própria bondade mediante a condenação do mal nos outros. O fato de denunciar os outros sempre foi uma forma poderosa e fácil de obter uma ideia elevada do seu próprio valor moral".

12 Connolly segue Nietzsche e Foucault a respeito da ligação entre cristianismo e humanismo. Para Foucault (2002, p. 472-473): "Nietzsche reencontrou o ponto onde o homem e Deus pertencem um ao outro, onde a morte do segundo é sinônimo do desaparecimento do primeiro, e onde a promessa do além-do-homem significa, primeiramente e antes de tudo, a iminência da morte do homem. Com isso, Nietzsche, propondo-nos esse 
dores, repressores do pluralismo e potencialmente violentos dessa perspectiva cristã e humanista moderna, Connolly quer deixar "a diferença ser", e, para tanto, quer abrir mais espaço para a luta de identidades que buscam o reconhecimento, mas, ao mesmo tempo, entende que, se o conflito se der por meio da compreensóes fundamentalistas de identidade e diferença, poderá ter resultados catastróficos para o próprio pluralismo. Diante deste problema, Connolly entende que a experiência do self acerca da contingência dos próprios fundamentos últimos das suas orientaçóes morais e políticas - que formam sua identidade -, e da interdependência entre identidade e diferença, poderia produzir "uma ética de respeito agonístico" em que "os adversários são respeitados e preservados", em vez de serem encarados como males a serem extirpados.

O conhecimento - por parte dos cidadáos e atores políticos, das contingências presentes na formação dos próprios self's e das suas identidades étnicas, religiosas, políticas - ocorreria por meio das genealogias. Para Connolly, não seria necessário que a genealogia se tornasse um tipo de conhecimento dominante em nossa cultura. A sua presença relevante como competidora com outras visóes já seria suficiente para desestabilizar fundamentalismos. Nesse sentido, Connolly fala em uma "política de perturbação", na qual "amigos, amantes e adversários" restringem a si mesmos por meio da "apreciação mútua das bases problemáticas a partir das quais atuam" (CONNOLLY, 1995, p. 29). Connolly (2005) entende que essa defesa de uma restrição a si mesmo não faz dele um relativista, mas alguém que defende uma concepção de bem, de tipo pluralista, que ele considera importante para a formação de cidadãos com um ethos pluralista entendido como importante para a democracia. A construção desse ethos estaria ligada a um trabalho sobre o próprio self que criaria um outro modo de sentir, mais favorável ao "respeito agonístico". A promoção do "respeito agonístico" seria também uma maneira de "enobrecer a democracia”|'.

Hatab (1995), em sua "defesa nietzschiana da democracia", sustenta que Nietzsche poderia ter defendido a democracia representativa se conhecesse

futuro, ao mesmo tempo como termo e como tarefa, marca o limiar a partir do qual a filosofia contemporânea pode recomeçar a pensar; ele continuará, sem dúvida, por muito tempo, a orientar seu curso..

13 Ver Connolly, 2000. 
melhor o seu funcionamento, e procura mostrar que a democracia não precisa se sustentar nos pressupostos metafísicos que foram criticados por Nietzsche. As compreensóes metafísicas de razão, verdade, igualdade e universalismo teriam produzido frequentemente resultados antidemocráticos ou totalitários. Em contraste, haveria uma afinidade eletiva entre finitude, contingência, perspectivismo, agonismo e democracia (HATAB, 1995). Hatab sustenta que a democracia pode ser defendida por uma "via negativa", que defenderia a inclusividade sem apelar a nenhuma ideia substantiva de igualdade, "simplesmente recusando-se a sancionar qualquer critério decisivo de exclusão" (HATAB, 1995, p. 84). Nesse sentido, o respeito agonístico pelos adversários, que Hatab chama de "respeito democrático", não dependeria de nenhuma afirmação substantiva, nem de um acordo simbólico mínimo (por exemplo, em torno de "liberdade" e "igualdade", como na formulaçáo de Mouffe), mas simplesmente do reconhecimento da finitude e contingência de todas as perspectivas, e, consequentemente, da ausência de qualquer critério definitivo para exclusão. Hatab pensa o reconhecimento dos adversários a partir da doutrina da vontade de poder de Nietzsche, que expressaria

[...] um campo agonístico de forças, onde qualquer conquista ou produção de valores é constituída pela superação de uma força oposta. Consequentemente, meu Outro está implicado na minha natureza e a anulação do meu outro seria a minha própria anulação [...], por isso, Nietzsche frequentemente fala sobre a necessidade de afirmar nossos oponentes enquanto oponentes, considerando que eles fazem parte do nosso próprio autodesenvolvimento. (HATAB, 1995, p. 68).

O respeito democrático se ligaria a uma "atitude básica essencial para a democracia", que seria assumir que: "de um ponto de vista político, nós devemos valorizar os procedimentos democráticos mais do que as nossas crenças" (HATAB, 1995, p. 67-68). A partir desta via negativa, Hatab (2002, p. 144) estaria disposto a abrir o agon para todas as perspectivas, inclusive aquelas que náo compartilham da defesa de liberdade e igualdade; isto faz da democracia um regime que assume o risco trágico de "morrer por suas próprias mãos". Assim, apesar de algumas especificidades, Hatab se insere na mesma linhagem de Connolly, marcada por uma apropriação de "Nietzsche para a democracia" de contornos predominantemente liberais, tanto por levar ao limite o ideal de "neutralidade" em relação a concepçóes abrangentes 
de "bem" materializadas nas diferentes perspectivas que disputam o poder, quanto pela posição favorável a um laisser aller cultural.

\section{Problemas nas apropriações agonísticas da filosofia de Nietzsche e limites do "respeito agonístico"}

Os teóricos políticos agonísticos buscam usar Nietzsche para radicalizar a democracia, um objetivo que, ainda que possa ser legítimo, não deixa de ser problemático, visto que Nietzsche foi um crítico da moralidade democrática moderna. Diversos comentadores já apontaram as dificuldades dessa leitura "democrática radical" de Nietzsche ${ }^{14}$.

Para Appel (1999, p. 161),

[...] a transferência de Nietzsche para o campo da democracia radical, como já observado, é frequentemente realizada por meio do colapso do seu trabalho no trabalho de Foucault ${ }^{15}$, cujo conhecido chamado ao não conformismo e à resistência contra 'normalizações' opressivas torna o discurso sobre o agon muito mais palatável para as sensibilidades democráticas.

Appel (1999) aponta uma domesticação do pensamento de Nietzsche para agradar a nossa sensibilidade democrática moderna, mas passando ao largo dos questionamentos mais profundos que Nietzsche fez à nossa moralidade, em vez de procurar respondê-los. Esse processo já acontecia nas apropriaçóes realizadas por Foucault e os demais pós-estruturalistas franceses. Por um lado, Foucault (1984 apud PINHO, 2009, p. 167) disse: "Sou simplesmente nietzschiano, e tento ver, na medida do possível, sobre certo número de pontos, com a ajuda de textos de Nietzsche - mas também com teses antinietzschianas (que são completamente nietzschianas!)

14 Os mais importantes críticos do uso de Nietzsche para a democracia são: Detwiler, 1990; Appel, I999; Dombowsky, 2004. Há também alguns trabalhos importantes no Brasil sobre o tema "Nietzsche e a democracia" (MARTON, 20II; DELBÓ, 2013; MATTOS, 2013; KAMRADT, 2017).

15 Connolly se apresenta como alguém que quer dar continuidade a essa "tradução" de Nietzsche para a democracia iniciada por Foucault e Deleuze, elaborando uma teoria política nessas bases, pois Foucault e Deleuze, "politizaram o espírito do pensamento de Nietzsche e assim reconstituíram algumas de suas dimensões-chave"; entretanto, "não levaram esse projeto longe o suficiente para sustentar uma teoria política" (CONNOLLY, 1991, p. 185) 
o que se pode fazer neste ou naquele domínio" ${ }^{16}$. Por outro lado, Foucault (1980, p. 53) também escreveu que: "A única marca de reconhecimento que se pode testemunhar a um pensamento como o de Nietzsche é precisamente utilizá-lo, deformá-lo, fazê-lo ranger, gritar. Então, que os comentadores digam se sou ou não fiel a ele não tem nenhum interesse" ${ }^{\text {"17 }}$. Não há nenhum problema nesse tipo de uso livre da obra de um filósofo, mas há limites para a razoabilidade das apropriaçóes. Parece pouco razoável, por exemplo, usar Marx para defender o anarcocapitalismo ou usar Hayek para defender o comunismo. No caso das apropriaçóes de Nietzsche feitas pelos pós-estruturalistas franceses e pelos teóricos agonísticos da democracia, os limites do razoável parecem ter sido cruzados em alguns sentidos. Por exemplo, a ênfase dos pós-estruturalistas na "resistência ao poder" não se realizaria ainda dentro do enquadramento moral cristão que Nietzsche critica? Esta ênfase no "ser contra" não seria reativa' Por que sempre o viés anti-institucional? Por que a dificuldade dos pós-estruturalistas franceses em exercer poder sem má consciência para fazer algo grande e criar instituiçóes duradouras? Os pós-estruturalistas de modo geral parecem celebrar o conflito como um bem em si e algo a ser estimulado, e resistem em ser explicitamente normativos em suas formulaçóes; entretanto, introduzem normatividade implícita e não justificada quando indicam o que seria um conflito desejável. Este viés normativo permanece implícito em Foucault, talvez seja perceptível apenas no tipo de conflito em que ele se engajou ${ }^{19}$, e não em discursos e textos, pois ele se recusava a

16 Resposta de Foucault na entrevista "Le retour de la morale", com G. Barbedette e A. Scala, em 29 maio 1984 (apud PINHO, 2009, p. 167).

17 Como se sabe, estes pensadores franceses utilizavam Nietzsche como "caixa de ferramentas". Deleuze, em entrevista com Foucault, afirmou: "Uma teoria é como uma caixa de ferramentas. Nada tem a ver com o significante [...] É preciso que sirva, é preciso que funcione. E não para si mesma. Se não há pessoas para utilizá-la, a começar pelo próprio teórico que deixa então de ser teórico, é que ela não vale nada ou que o momento ainda não chegou. Não se refaz uma teoria, fazem-se outras; há outras a serem feitas" (FOUCAULT, 20I2, p. I32).

18 Acampora (2003, p. 377) também destaca a centralidade do agon no pensamento de Nietzsche, mas distingue-se dos pós-estruturalistas e agonistas quando entende que, para Nietzsche, o agon é um meio social e cultural para a criação de um senso de bem público e para a criação de valores, e "não uma atividade para promover a reatividade e a "contestação incessantes'”. Ver também: p. 30I-324.

19 A postura a priori em favor de "resistência" - mesmo que essa resistência seja liderada por Aiatolás, como no caso do apoio de Foucault à revolução iraniana de 1979 - não seria derivada daquela sensibilidade cristã que desconfia dos poderosos "deste mundo" e tende a dar razão a priori aos "fracos"? Contra o "imperialismo" americano e em favor da revolução dos Aiatolás, pois são o lado mais fraco; mas, quando Foucault escolheu 
explicitar seus pressupostos normativos e a argumentar em termos normativos, como fica claro no debate dele com Chomsky (FOUCAULT, 2010, p. 87-132). Alguns foucaultianos e deleuzianos norte-americanos operam dentro da mesma normatividade; mas, ao contrário de Foucault e Deleuze, a tornam explícita. Thiele (1990, p. 921), por exemplo, afirma que para Foucault nem "[...] todas as formas de conflito são igualmente meritórias ou desejáveis. $\mathrm{O}$ aprimoramento do conflito - não sua mera produção ou exacerbação - deve formar o critério do juízo político". Entretanto, continuamos sem saber explicitamente porque devemos defender o conflito sem apelar a razóes normativas que justifiquem a entrada em um conflito. Thiele (1990, p. 921) prossegue: “[...] a luta por riqueza desordenada, por exemplo, pode ser justificadamente reduzida, porque ela significa em sua fruiçấo o desempoderamento dos membros empobrecidos da comunidade política”. Assim, Thiele enxerga em Foucault uma exclusão de determinados conflitos do campo dos conflitos legítimos. Isso não envolve uma domesticaçáo do conflito a partir de um critério normativo externo ao conflito? Não há problema nenhum em ser normativo, o problema é que Foucault nega que o seja. Não opera aí um critério normativo não explicitado que excluiu do campo dos conflitos legítimos a "luta por riqueza desordenada”? O critério normativo por trás desta exclusão não parece ser nem a grandeza, nem a excelência (que seriam mais afins com o pensamento de Nietzsche), pois não se trata de uma crítica à falta de nobreza de uma vida dedicada ao lucro. Seria então um critério normativo derivado da moral da compaixão criticada por Nietzsche? Por que o impulso por lucro, ou um impulso mais perigoso como a ânsia de domínio, são excluídos neste processo de "aprimoramento" do conflito? Por que diminuem a chance de grandeza ou por que causam sofrimento (compaixão)? O que se critica no poder de uns homens sobre outros é o possível sofrimento que decorre dessa relaçáo ou a qualidade daquilo que essas relaçóes de poder produzem para a "economia global da vida"20? Excluir estes impulsos "imorais" do campo de conflitos legítimos não poderia ter também efeitos ruins para a "economia global da vida"? Os pós-estruturalistas franceses e os teóricos

onde ir morar ou passar férias, transitou entre Paris e San Francisco. Ver: Afary, Anderson e Foucault, 201 I.

20 Sobre "economia global da vida" (im Gesamt-Haushalte des Lebens), confira: BM, §23; veja, também: BM §44 e $§ 62$ (NIETZSCHE, 2005). 
agonísticos da democracia não enfrentam com a devida atenção este gênero de questóes nietzschianas relacionadas com a "economia global da vida", porque isso envolveria colocar em avaliação os seus próprios pressupostos morais. Em vez disso, exaltam o conflito como um bem em si, mas, ao mesmo tempo, exigem sua domesticação a partir de critérios normativos, implícitos ou explícitos, que Nietzsche não teria dificuldade em apontar como derivados da moral cristâ. Afinal, como é amplamente conhecido, para Nietzsche (2005), o "movimento democrático constitui a herança do movimento cristão" 2 , pois teria radicalizado certos pressupostos normativos cristãos (moral da compaixão, igualitarismo, veracidade) e resultado em "misarquismo", anarquismo, socialismo, "democratismo" e outras tendências modernas criticadas por Nietzsche que faziam parte da grande família política em que se formariam e militariam os intelectuais pós-estruturalistas e agonísticos. A própria motivação a partir da qual estes teóricos recorrem à ideia de agon é distinta daquela de Nietzsche, pois ele entendia o agon grego como uma forma de dar medida aos impulsos agressivos e que seria diferente dos "remédios radicais" oferecidos pelo platonismo e cristianismo (tais como a tirania da razão e a tentativa de extirpar a parte que julgavam inumana da natureza humana). Os gregos, em contraste com estes remédios radicais, teriam oferecido, segundo Nietzsche, uma forma de medida civilizatória não radical, uma medida trágica, por meio do agon, que, em vez de extirpar a "parte inumana", ou "maldita", da natureza humana, procurava "sublimá-la”, estilizá-la, embelezá-la e canalizá-la para o bem da $p{ }_{i s^{22}}$. Os teóricos agonísticos modernos, por sua vez, recorrem ao agon para aprofundar a revolução democrática dos tempos modernos, a qual, ao menos na sua vertente radical, representava para Nietzsche uma continuaçáo e radicalizaçáo secularizada da moral cristá.

Connolly e Hatab vão além dos usos tópicos que pós-estruturalistas franceses faziam das "ferramentas" de Nietzsche e pretenderam ser "nietzschianos”. Evidentemente, eles não ignoram as críticas de Nietzsche à moralidade democrática moderna, mas se desfazem rápido demais delas e pro-

21 Cf. BM, §202 (NIETZSCHE, 2005a).

22 Ver, por exemplo, dois textos de Nietzsche: "A disputa de Homero" (DH) (2005) e (CI), "Moral como antinatureza”, §I e $\S 3(2010)$. 
duzem interpretaçóes da obra de Nietzsche que são exegeticamente pouco rigorosas ${ }^{23}$. Assim, Nietzsche é domesticado, tornado inofensivo ao nosso gosto moral. Connolly (1991, p. 161), por exemplo, diz encontrar duas éticas possíveis a partir da "ontologia da resistência" nietzschiana, expressa em sua hipótese do mundo como vontade de poder: 1) a primeira entende a vontade de poder de modo mais estreito e aconselha a humanidade a completar o seu projeto assumindo o domínio da terra, aceitando a implicação de que muitos seres humanos teráo que ser subjugados por poucos para atingir estes fins. Essa ética estaria ligada impulso moderno para o domínio do mundo; 2) A segunda ética, também fundada na mesma ontologia da resistência, nos levaria a entrar em acordo com a diferença e deixar a diferença ser. "Seria uma ética do deixar acontecer" (CONNOLLY, 1988, p. 161, grifos meus). Ora, não existe essa divisão sanitária na obra de Nietzsche entre uma vontade de poder que visa ao "domínio do mundo" e outra que quer apenas "deixar a diferença ser". Se levarmos a sério os escritos de Nietzsche, é verdade que não podemos reduzir a "vontade de poder" a uma vontade de dominar, tampouco podemos excluir essa vontade de dominar do campo de possibilidades da "vontade de poder". As vontades de poder vão até onde conseguem ir, iriam até a supremacia, se pudessem ${ }^{24}$.

Tampouco encontramos em Nietzsche alguma aposta na autolimitação psicológica dos sujeitos, tal como supóe a ideia de "respeito agonístico", para impedir o impulso ao domínio ou levar atores a abraçarem uma ética do "deixar acontecer". Este é um dos principais limites do "respeito agonístico": o déficit de realismo implicado nessa proposição normativa. $\mathrm{O}$ que garante que os indivíduos estaráo dispostos a ingressar em um empreendimento genealógico para descobrir que os seus próprios fundamentos últimos são contingentes e construídos e, portanto, contestáveis aos olhos de outros? Por que eles quereriam autolimitar sua tendência ao fundamentalismo deflacionando suas próprias concepçóes morais e políticas? Por que eles abdicariam de tentar fazer suas próprias concepçóes de bem prevaleceram sobre outras? Ainda que alguns indivíduos possam querer

23 Concordamos com Siemens (2013, p. 83) quando afirma que os teóricos agonísticos "ignoram, menosprezam ou abrandam" as críticas de Nietzsche à democracia.

24 Ver, por exemplo, A Vontade de Poder - VP, §776 (NIETZSCHE, 2008b) e comparar com o que Connolly (1988, p. 194) escreve sobre a vontade de poder. 
enveredar por esse caminho, quando expostos às genealogias históricas de suas próprias crenças, o que garante que a maioria também o fará? Para Siemens (2013), um problema das apropriaçóes de Nietzsche feitas por Connolly e Hatab é que eles colocam a questão dos limites do agon a partir da posição do sujeito, que precisaria reconhecer a interdependência implicada nas relaçóes de antagonismo. Entretanto, Siemens insiste, a nosso ver corretamente, que os limites do agon para Nietzsche não se realizariam a partir da perspectiva do sujeito, mas de um equilíbrio "externo" entre forças mais ou menos iguais que seria forjado por instituições. Siemens cita textos importantes de Nietzsche para sustentar essa tese, incluindo a passagem, em A Disputa de Homero, sobre o papel do ostracismo na Atenas clássica. Na visão de Nietzsche, prossegue Siemens (2013, p. 91): “[...] o equilíbrio é, portanto, um fenômeno relacional e intersubjetivo, uma função das relações entre forças mais ou menos iguais, cada qual lutando pela supremacia"; isto "[...] introduz uma disjunção radical entre a posição de sujeito dos antagonistas - seus desejos, intenções e aspiraçóes - e as qualidades que resultam da interação agonal: todos querem ser os melhores, ainda assim um equilíbrio é, ou pode ser, atingido". Para Siemens, não é o respeito que motiva ou limita a ação agonal, pois o equilíbrio não é o objetivo consciente dos sujeitos, eles não lutam pelo equilíbrio, mas pela supremacia. Assim, em comparação com Connolly e Hatab, Nietzsche teria "[...] uma visão mais realista das disposiçóes subjetivas", colocando ambição, ciúme, inveja e ódio como "paixões que são as fontes reais do agon" (SIEMENS, 2013, p. 92).

De forma geral, podemos dizer que os teóricos agonísticos que se referenciam em Nietzsche apresentam uma descrição quase nietzschiana do real e uma prescrição normativa bastante distinta da nietzschiana (e talvez mesmo oposta a ela). O real é descrito a partir da vontade de poder, traduzida pela "teoria das forças" (da interpretação foucaultiana e deleuziana de Nietzsche) e se transforma em uma “ontologia da resistência”. Não há fundamentos absolutos, o real é múltiplo e em devir, nenhum sujeito ou identidade possui uma essência verdadeira e única com uma origem própria, todo sujeito ou identidade é internamente múltiplo em devir e está em relação (agonística ou antagonística) com outras identidades. Essas relaçóes de poder são constitutivas do sujeito e das identidades. A partir 
dessa descrição do real, entretanto, os teóricos agonísticos extraem a seguinte conclusão normativa: se não há fundamento (ou essência) verdadeiro do sujeito e das identidades não há critérios para justificar interdiçôes ou exclusóes. Temos, portanto, a conclusão liberal de "deixar a diferença ser" e "deixar acontecer", para usar as palavras de Connolly.

Hatab funda sua defesa da democracia e do respeito democrático por adversários nesta mesma ética do "deixar acontecer". Para Hatab, uma "democracia 'pós-moderna" pode defender a inclusividade sem apelar a uma ideia substantiva de igualdade simplesmente "[...] recusando-se a sancionar qualquer critério decisivo de exclusão, desde que o pós-modernismo suspeita do fornecimento de privilégio a qualquer discurso" (1995, p. 84). Não interditar nem sancionar: deixar acontecer. Para Hatab (1995, p. 67), o "respeito democrático" não depende de uma apreciação positiva dos adversários (como ele julga que Connolly faz); mas, depende "[...] do reconhecimento da finitude e da contingência das crenças e interesses de cada um”. Neste ponto, o autor afirma que se coloca do lado do liberalismo em seu debate com o comunitarismo porque critica a tentativa de definir uma comunidade política em uma sociedade pluralista, pois ela "[...] leva ao problema de suprimir ou remover diferenças, especialmente à luz de um poder coercitivo institucional que marca a esfera política” (HATAB, 1995, p. 189). Para Hatab, os comunitaristas teriam "nostalgia por um sentido perdido de comunidade", que náo faria sentido em nossos "tempos fracionados" e a "harmonia" de comunidades do passado "[...] se devia mais a exclusóes de certos grupos da participação política, ou do isolamento de diferentes grupos culturais em seus próprios enclaves" (1995, p. 190). Enfim, na ausência de fundamentos absolutos, segundo Connolly e Hatab, não teríamos critérios para interditar ou excluir, portanto, definir valores predominantes em uma comunidade ou "dar forma ao homem" seria algo não legítimo, sendo preferível "deixar acontecer".

Para Nietzsche, em contraste com os teóricos agonísticos, justamente porque não existem fundamentos absolutos e formas "verdadeiras" é que devemos "dar forma ao homem". O homem é um "animal ainda não determinado" (NIETZSCHE, 2005) ${ }^{25}$ que precisa de formas sociais para viver. "Dar forma" envolve exercer poder para governar, incorporar, dirigir,

25 Cf. BM, $\$ 62$. 
estimular, reprimir, excluir, coagir etc. Isso pode causar sofrimento. Entretanto, o sofrimento não constitui, para Nietzsche, uma objeção ao ato de "dar forma". A moral é uma das mais poderosas maneiras de "dar forma" ao homem. Coerção e arbitrariedade estáo na sua origem, mas isso não constitui, para Nietzsche, objeção nem ao ato de dar forma nem à moral. A este respeito, Nietzsche é bem explícito:

Toda moral é, em contraposiçáo ao laisser aller, um pouco de tirania contra a "natureza", e também contra a "razão": mas isso ainda náo constitui objeçáo a ela, caso contrário se teria de proibir sempre, a partir de alguma moral, toda espécie de tirania e desrazão. O essencial e inestimável em toda moral é o fato de ela ser uma demorada coerçáo [...]. Mas o fato curioso é que tudo o que há e houve de liberdade, finura, dança, arrojo e segurança magistral sobre a Terra, seja no próprio pensar, seja no governar, ou no falar e convencer, tanto nas artes como nos costumes, desenvolveu-se apenas graças à "tirania de tais leis arbitrárias"; e, com toda a seriedade, não é pequena a probabilidade de que justamente isso seja "natureza" e "natural" - e náo aquele laisser aller! [...] O essencial, "no céu como na terra", ao que parece, é, repito, que se obedeça por muito tempo e numa direçáo: daí surge com o tempo, e sempre surgiu, alguma coisa pela qual vale a pena viver na terra, como virtude, arte, música, dança, razáo, espiritualidade [...] Considere-se toda moral sob esse aspecto: a "natureza" nela é que ensina a odiar o laisser aller, a liberdade excessiva, e que implanta a necessidade de horizontes limitados, de tarefas mais imediatas - que ensina o estreitamento das perspectivas, $e$ em determinado sentido também a estupidez, como condiçáo de vida e crescimento. (NIETZSCHE, 2005a, pp. 76-78, grifos meus). ${ }^{26}$

Os humanos são seres que produzem valores e sentem necessidade de valores. Toda moral é "um pouco de tirania contra a 'natureza", ou seja, uma coerção que dirige, molda, exclui e reprime alguns impulsos naturais nos humanos, enquanto libera outros impulsos. Mas a coerção "não constitui objeção" a uma moral, pois todas as morais são assim e, não obstante, alguma moral é sempre necessária ${ }^{27}$. Nietzsche vai além, em tom

26 Cf. BM, §I88.

27 "A crítica de Nietzsche à moral, mesmo quando ganha contornos de desconfiança e de ceticismo, não pode ser confundida com uma ação inconsequente de destruição. Isso se torna claro, por exemplo, quando ele defende o princípio do dever, característica básica de toda moral (cf. GD/Cl, Moral como contranatureza, § 4), em oposição ao laisser aller (cf. JGB/BM § I88); quando declara que a moral está entre as coisas que mais compensam serem levadas a sério (cf. GM/GM, Prólogo, § 7); e também quando se refere à severa disciplina, necessária para levar a cabo seu trabalho crítico (cf. WA/CW, Prefácio)” (PASCHOAL, 2002, p. 55). Ver também: Brobjer, 1995; Leiter, 2002; Tongeren, 2012; Lopes, 2013. 
deliberadamente polêmico, e afirma que o "essencial é o fato de ela ser uma demorada coerção", pois assim canaliza e organiza as forças, os impulsos, dando-lhes alguma hierarquia e sentido, dando forma ao homem, criando papéis sociais, criando, enfim, uma cultura. O essencial, prossegue Nietzsche (2005a, p.77: "é que se obedeça por muito tempo e numa direção". Tal como um pianista, que treina desde os seis anos de idade durante muitas horas por dia, repetindo disciplinadamente os mesmos exercícios, "estreitando" suas perspectivas ao recusar outros exercícios ou uma introduçáo precoce às improvisaçóes. O jovem pianista deve obedecer, repetindo os mesmos paradigmas de seus mestres durante longo tempo. "Estreitar" perspectivas de tal maneira pode ser estupidez, do ponto de vista de um "espírito livre", mas esta estupidez pode ser "condição de vida e crescimento". Somente depois desta demorada coerção, desta longa disciplina e do estreitamento de perspectivas - esta estupidez - o pianista do nosso exemplo terá acumulado forças, saberes e práticas que o tornariam capaz de superar os velhos paradigmas e criar e improvisar com maestria. Em contraste, o laisser aller, ao rejeitar de forma geral coerção, estreitamento e disciplina, dificultaria, segundo Nietzsche (2009), o acúmulo de forças. O laisser aller dispersa e desagrega as "forças", estimulando, portanto, a décadence $e^{28}$.

O que os pós-estruturalistas franceses e os teóricos agonísticos fazem é precisamente promover o laisser aller. Tomemos, por exemplo, um texto de Deleuze que Connolly citou no final do seu livro Ethos of Pluralization: "Não devemos mais acreditar em árvores, em raízes ou radículas, já sofremos muito" (DELEUZE, 1995, p. 24, grifos meus). Neste livro, Deleuze e Guattari buscam um novo modelo epistemológico e criam uma oposição binária metafórica entre árvore e rizoma. "Árvore”, remete a uma raiz comum, a uma "essência" que "impóe" uma unidade. "Rizoma”, em contraste, é um tipo de planta cujos brotos podem se ramificar em qualquer ponto,

28 "Como se caracteriza toda décadence literária? Pelo fato de a vida não mais habitar o todo. A palavra se torna soberana e pula fora da frase, a frase transborda e obscurece o sentido da página, a página ganha vida às expensas do todo - o todo já não é mais um todo. Mas isto é uma alegoria para todo estilo da décadence: a cada vez, anarquia de átomos, desagregação da vontade, 'liberdade individual', em termos morais - estendendo à teoria política, 'direitos iguais para todos'” - Cf. CW §7 (NIETZSCHE, 2009). Para Nietzsche, laisser aller está relacionado com "democratismo" e este "sempre foi a forma de declínio da força organizadora" - Cf. Cl, Incursões de um extemporâneo, §39. Ver também §4I, na mesma seção (NIETZSCHE, 20I0). 
quer dizer, não seguem linhas de subordinação hierárquica. Ora, o rizoma é laisser aller. É como se os galhos do rizoma escrevessem na areia "é proibido proibir”. Não se trata apenas de um novo olhar epistemológico, é um novo modo de vida que é desejado por Deleuze. Ou seja, admitidamente ou não, as formulaçóes de Deleuze têm pretensóes normativas. Para Deleuze, uma sociedade inspirada no modelo do rizoma seria melhor que uma sociedade "arborescente" (DELEUZE, 1995, p. 24). É nesse sentido que ele afirma que "A árvore é filiação, mas o rizoma é aliança, unicamente aliança. A árvore impóe o verbo 'ser', mas o rizoma tem como tecido a conjunção "E... E... E...”. Há nesta conjunção força suficiente para sacudir e desenraizar o verbo ser" (DELEUZE, 1995, p. 36). A conjunção "e" é mais democrática, ela nunca impóe, ela não exclui como a conjunção "ou". "E” é laisser aller. "Filiação" é algo pesado demais, pois é algo que não é livremente escolhido. Os defensores do laisser aller querem "leveza" e desoneração, e não peso e responsabilidade. Consideram bom apenas aquilo que se deseja "livremente". Essa liberdade maior desejada, entretanto, não vem acompanhada de mais responsabilidade, mas sim de uma alegre "bela irresponsabilidade" 29 , que foi sedutora para muitos jovens dos anos 1960 nos países ocidentais. Para eles, seria melhor algo mais fluído que "árvore" ou "filiação". Enfim, o Rizoma oferece uma imagem que satisfaz plenamente a moralidade do laisser aller e o desejo de livrar-se. Por isso: "Não devemos mais acreditar em árvores, em raízes ou radículas, já sofremos muito" (DELEUZE, 1995, p. 25). Entretanto, como indicamos, Nietzsche (2005) nunca considera o "sofrimento" como uma objeçáo ao ato de dar forma, o ato de criar uma unidade a partir da multiplicidade. Ele associa este excesso de sensibilidade com o sofrimento à fraqueza trazida pelo cristianismo e sua moral da compaixão, que criou "homens sem dureza e elevação suficientes para poder, como artistas, dar forma ao homem" (NIETZSCHE, 2005, p.61) ${ }^{30}$.

Connolly explicitamente parte das leituras francesas de Nietzsche presentes nas obras de Foucault e Deleuze. Hatab também compartilha este

29 Em uma das "deformações" que fazem "ranger" o pensamento de Nietzsche, como defendia Foucault, Deleuze associa Nietzsche à "bela irresponsabilidade”: "O 'sim' de Nietzsche opõe-se ao 'não' dialético; a afirmação à negação dialética; a diferença, à contradição dialética; o gozo, o prazer, ao trabalho dialético; a leveza, a dança, à gravidade dialética; a bela irresponsabilidade, às responsabilidades dialéticas” (DELEUZE, 2001, p. 17).

30 Cf. BM, $§ 62$. 
viés francês de interpretação da filosofia de Nietzsche e os mesmos compromissos normativos de Connolly. Hatab explicita a diferença entre sua posição e a de Nietzsche, mas acredita poder demonstrar que, para ser coerente com seus próprios pressupostos, o autor de Além do Bem e do Mal deveria ser um democrata agonístico pós-moderno. Hatab enxerga um paradoxo em Nietzsche, pois afirmou o perspectivismo e o antifundacionalismo, "que torna todas as garantias políticas fixas suspeitas", e, ao mesmo tempo, defendeu a "grande política", e, com isso, teria "[...] sucumbido de alguma forma a uma versão política do tipo de fechamento e grandeza que ele frequentemente desprezava" (HATAB, 1995, p. 137). Este paradoxo realmente existe em Nietzsche e em seus próprios termos? Existiria se a ausência de "fundamento" servisse de argumento para uma recusa "a sancionar qualquer critério decisivo de exclusão" (HATAB, 1995, p. 84). Mas seria esta recusa simplesmente demonstrável a todos os seres racionais ou dependeria do compartilhamento de determinadas premissas normativas cujos fundamentos últimos também não podem ser provados racionalmente? O paradoxo existiria se Nietzsche compartilhasse as premissas normativas de que "todos os indivíduos são iguais" e que "nenhuma perspectiva se justifica meramente por ser uma vontade, quer dizer, uma arbitrariedade". Entretanto, para Nietzsche, uma consequência da "morte de Deus" é que todas as perspectivas morais e políticas em última instância têm um fundamento arbitrário (humano, contingente e construído). Além disso, na visão de Nietzsche, os indivíduos não são iguais e alguma hierarquia (entre forças e perspectivas) é sempre necessária para formar qualquer "unidade", seja ela um indivíduo, uma cultura ou um Estado. Como vimos, Nietzsche não se coloca contra o ato de "dar unidade". Se os fundamentos são arbitrários, as hierarquias, no limite, também são arbitrárias, e, não obstante, são necessárias para a vida. Um "artista” não teria problema em criar uma hierarquia e dar forma a partir de bases arbitrárias. Para um democrata moderno ou "pós-moderno", em contraste, é mais difícil justificar uma hierarquia. Ainda mais difícil é justificar uma hierarquia cujas fundaçôes são arbitrárias. Para Nietzsche, como apontamos, essa dificuldade é expressão da fraqueza trazida pelo cristianismo (igualdade e moral da compaixão). O problema, para Nietzsche, não seria o "relativismo" de teóricos como Connolly e Hatab, mas sim sua fraqueza e falta de "realismo". $\mathrm{O}$ entendimento que Nietzsche tinha dos sofistas nos ajuda a esclarecer este ponto: no mundo pré-cristão, os sofistas já eram "relativistas". Para 
Nietzsche (2008b, p. 239-230), os sofistas eram "artistas" e "realistas" o suficiente para dar forma; não sentiam nenhum "paradoxo" em sua própria atuação, não se incomodavam com a sua própria "imoralidade", qual seja, de saber que seus próprios fundamentos eram arbitrários e, ainda assim, defendê-los para "hierarquizar" ${ }^{31}$. Portanto, Connolly e Hatab procuram fundar suas teorizaçóes em Nietzsche, mas suas conclusóes políticas são bastante distintas, pois partem de premissas normativas que são radicalmente contestadas pelo filósofo alemão, sendo contraditórias com o seu projeto geral. O que nos leva a pensar na pertinência da escolha de Nietzsche como referência central para seus projetos normativos.

De modo geral, pós-estruturalistas e agonistas tomam textos em que Nietzsche está descrevendo o real como se ele estivesse prescrevendo. Isso ocorre no caso da ontologia da vontade de poder, que se transforma em "ontologia da resistência” (NIETZSCHE, 2008b). A partir da descrição nietzschiana da ausência de fundamento e do caráter contingente e relacional de todas as identidades, os pós-estruturalistas e agonistas concluem uma prescrição normativa de promover a desconstrução para expor - a todos - o caráter múltiplo, contingente e relacional de todas as identidades e denunciar todas as tentativas "normalizadoras" de dar unidade e permanência. Entretanto, como vimos antes, para Nietzsche é preciso "dar forma ao homem”. Da multiplicidade, é preciso criar unidade. A coerção e o sofrimento não constituem em si objeção a essa necessidade, exceto para "homens sem dureza e elevação suficientes". Ao contrário da "bela irresponsabilidade" deleuziana, para Nietzsche (2005a), homens elevados, por exemplo, os "filósofos do futuro", saberiam assumir a responsabilidade de "dar forma ao homem", saberiam criar instituiçóes duradouras (não efêmeras nem rizomáticas) ${ }^{32}$.

Assim, Nietzsche poderia dizer que os pós-estruturalistas e teóricos agonísticos não possuiriam as condiçôes necessárias para essa tarefa. Afinal,

31 Conforme VP, §429: “[...] os sofistas não são nada mais do que realistas: formulam todos os valores e práticas usuais para hierarquização dos valores, - têm a coragem, própria a todos os espíritos fortes, de saber de sua imoralidade [...]" (NIETZSCHE, 2008b, p. 239-230).

32 Há inúmeras passagens em que Nietzsche revela-se favorável à reverência e à permanência como características do que é "nobre". É nesse sentido, por exemplo, que ele escreve: "O modo como em geral se manteve na Europa a reverência pela Bíblia, até os dias de hoje, é talvez o melhor exemplo de disciplina e refinamento de costumes que a Europa deve ao cristianismo: semelhantes livros, de profundidade e extrema significação, requerem uma tirania de autoridade externa para sua proteção, a fim de conquistar os milênios de permanência que são precisos para esgotá-los e decifrá-los” - Cf. BM, §263 (NIETZSCHE, 2005a). 
[...] para que haja instituições, é preciso haver uma espécie de vontade, de instinto, de imperativo antiliberal até a malvadeza: a vontade de tradição, de autoridade, de responsabilidade por séculos adiante, de solidariedade entre cadeias de geraçóes, para frente e para trás in infinitum. (NIETZSCHE, 2010, p. 89) $)^{33}$.

Para colocar Nietzsche a serviço do laisser aller ${ }^{34}$, os pós-estruturalistas franceses e os teóricos agonísticos precisam fazer uma seleção cuidadosa dos textos de Nietzsche para evitar passagens como esta. Nesse esforço, é comum que prefiram textos do "período intermediário" da filosofia de Nietzsche ou que selecionem passagens em que Nietzsche está escrevendo sobre os espíritos livres e filósofos. A partir destas passagens extrapolam conclusóes prescritivas para todos os humanos, como se o que Nietzsche escreveu sobre espíritos livres e filósofos fosse, para ele, algo válido para todos os seres humanos. Entretanto, para Nietzsche: "Os homens não são iguais'. E tampouco deverão sê-lo!” (NIETZSCHE, 2011, p. 96) ${ }^{35}$. Não se trata, em Nietzsche, de uma defesa da desigualdade motivada por egoísmo, alguma tentativa de defender para si algum privilégio excluindo os demais dos tesouros. Trata-se da constatação - semelhante à de pensadores clássicos como Platão - da diferença entre indivíduos, da consideração que diferentes indivíduos têm habilidades e possibilidades diferentes cuja origem não pode ser reduzida apenas ao meio social. Nesta visão, forçar uma homogeneidade de modos de vida e morais a partir de um igualitarismo abstrato produziria efeitos nocivos para a cultura como um todo e para os próprios indivíduos. Por exemplo, defender que todos sejam tão críticos, autônomos e "desconstruídos" como os "espíritos livres" poderia produzir efeitos nocivos em muitas pessoas. Para Nietzsche, nem todos os humanos suportariam viver como um "espírito livre", que “[...] se despede de toda crença, todo desejo de certeza, treinado que é em se equilibrar sobre tênues cordas e possibilidades e em dançar até mesmo à beira de abismos" (NIETZSCHE, 2005, p. 241?)36. O "problema da verdade" em Nietzsche não tinha apenas uma dimensão epistemológica. Também possuía uma dimensão psicológica com implicações sociais e políticas e que

33 Ver: Cl, Incursões de um Extemporâneo, §39.

34 Sobre o "hiperliberalismo" de Foucault, ver Beiner, 1995.

35 Em Assim Falou Zaratustra (Z, Das tarântulas).

36 Gaia Ciência (GC, §347). 
se articulava em torno das questóes: é possível universalizar a vida filosófica? Quais seriam as consequências da corrosão do mito pelo racionalismo? A vida do "espírito livre" é universalizável? O iluminismo apostou nesta possibilidade, pois queria uma sociedade em que a autonomia de cada indivíduo como sujeito racional e crítico fosse uma realidade universal, ainda que esse processo de esclarecimento pudesse ser concebido por alguns pensadores iluministas como gradual e aproximativo. O projeto iluminista partia de uma premissa igualitária: a sociedade esclarecida é um projeto possível porque os homens são iguais, não há diferenças naturais relevantes, basta removermos os obstáculos sociais e históricos que mantêm a maioria na "heteronomia" e todos, mais cedo ou mais tarde, seráo indivíduos autônomos e críticos. Este projeto iluminista não é colocado em exame na reflexão de Connolly e Hatab e parece ser pressuposto como possível e desejável; afinal, mesmo que eles não imaginem que todos um dia seriam filósofos e espíritos livres, o que eles exigem de um indivíduo imbuído de "respeito agonístico"? Que ele tenha tanta "autonomia", senso crítico e flexibilidade quanto um "espírito livre" de Nietzsche... Pois teria que passar por empreendimentos genealógicos para conhecer a contingência dos fundamentos últimos de seus próprios pressupostos morais e políticos e, com isso, deflacionar suas próprias tendências ao fundamentalismo. A ideia de respeito agonístico depende da pressuposiçáo de que, em tese, todos os humanos (ou ao menos um grande número deles) podem seguir esse caminho de espíritos livres ou "filósofos".

Nietzsche nunca teve essa fé. Nunca acreditou na possibilidade de universalizar o estilo de vida de espíritos livres e filósofos. Com os iluministas, Nietzsche tinha em alta estima a vida filosófica, mas diferente deles, sempre considerou que ela náo seria para todos. Essa reserva de Nietzsche aparece desde os primeiros textos até os últimos.

Na Segunda Consideração Extemporânea, Nietzsche (2003, p. 84, grifos meus $)^{37}$ escreveu sobre "verdades mortais" descobertas na filosofia, as quais seriam nocivas se o povo as descobrisse:

37 Conforme consta em Segunda Consideração Intempestiva: da utilidade e desvantagem da história para a vida ( KSA I.319, Co. Ext. II, § 9). 
Se, ao contrário, as doutrinas do vir a ser soberano, da fluidez de todos os conceitos, tipos e gêneros, da falta de toda diferença cardinal entre homem e animal - doutrinas que tomo por verdadeiras, mas letais - no furor habitual por instrução, sejam ainda jogadas no povo durante uma geração, então ninguém deve se espantar se o povo naufragar no que é egoisticamente pequeno e miserável, na ossificação e ganância, ou seja, para ser, antes de mais nada, povo mutilado e extinto: no seu lugar talvez adentrem na arena do futuro um sistema de egoísmos singulares, irmandades visando à exploração abusada dos não irmãos, e criações similares da vulgaridade utilitária.

Em Gaia Ciência, Nietzsche também refletiu sobre a questão: "Até que ponto a verdade suporta ser incorporada?" (2005, p. 139) ${ }^{38}$. Em Ecce Homo, Nietzsche pergunta "quanta verdade suporta, quanta verdade ousa um espírito? (2008a, p. 16? $)^{39}$. Afinal, quem garante que a busca da verdade seja inofensiva e inofensiva para todos? Por que todos deveriam ser expostos ao possível sofrimento causado pela busca da verdade a todo custo, uma busca que pode encontrar ao fim o abismo da falta de fundamento? Todo filósofo profundo, diz Nietzsche, "tem mais receio de ser compreendido do que mal compreendido". Afinal, ser mal compreendido agrediria apenas a sua vaidade como escritor, mas quando muitos compreendem o filósofo profundo: "[...] sofrerá o seu coração, sua simpatia, que sempre diz: "Oh, porque desejam também passar por essas coisas?" (2005a, p. 175?) ${ }^{40}$. A este respeito, Connolly e Hatab estão em antagonismo com Nietzsche, pois defendem a exposiçáo aberta e universal do caráter construído e contingente dos fundamentos de todas as morais, para deflacionar a tendência ao fundamentalismo e promover o "respeito agonístico". Nietzsche, como indicamos, expressou em algumas ocasióes a preocupação de que essa exposição promoveria o niilismo, tendo efeitos nefastos na vida humana. Em uma linguagem que Nietzsche utilizaria mais tarde, a exposição a todos das verdades mortais na melhor hipótese levaria ao "último homem"

\footnotetext{
38 Trecho do $\$ 110$.

39 EH, Prólogo, §3.

40 Cf. BM, § 290.

4 I Cf. Z, Prólogo, §5: "A Terra se tomou pequena, então, e sobre ela saltita o último homem, que torna tudo pequeno. Sua estirpe é indestrutível, como a pulga; o último homem é o que vive mais tempo. 'Nós inventamos a felicidade'- dizem os últimos homens, e piscam os olhos [...]. Nenhum pastor e um só rebanho! Todos querem o mesmo, todos são iguais. Quem sente de outra maneira vai voluntariamente para o hospício. 'Outrora o mundo era doido' - dizem os mais refinados, e piscam o olho. São inteligentes e sabem de tudo o que ocorreu: então sua zombaria não tem fim. Ainda brigam, mas logo se reconciliam - de outro modo, estraga-se o estômago. Tem seu prazerzinho para o dia e seu prazerzinho para a noite, mas respeitam a saúde" (NIETZSCHE, 20II)
} 
ele significava um triste rebaixamento das expectativas humanas, pois tornaria cada vez mais raras a excelência, a grandeza e a criação. A hipótese levantada por Nietzsche é que expor todos à busca fugidia pela verdade, ao "vir a ser soberano" e ao perspectivismo levaria ao enfraquecimento de coisas que pressionavam os humanos a buscar excelência - como Deus ou o ideal clássico de virtude - e, com isso, abriria as portas para o filistinismo, preguiça e covardia desimpedidos.

Para evitar estes efeitos nocivos para a espécie, ao invés de expor de forma aberta a atividade filosófica, seria preciso selecionar a audiência. Isso implicaria conter o iluminista "furor habitual por instrução". Nietzsche chega a estas conclusões a partir da sua longa reflexão sobre a verdade como problema, questáo relacionada com problema da relaçáo entre filosofia e sociedade. A partir de Além do Bem e do Mal Nietzsche se afasta de forma mais nítida da posição iluminista, que apostava na universalização e realização da filosofia ${ }^{42}$. Apesar das suas conhecidas críticas a Platão, Nietzsche se aproxima da posição platônica a respeito da relaçáo entre filosofia e sociedade. Esse peculiar "platonismo" apareceria especialmente em Além do Bem e do Mal, livro em que, segundo Leo Strauss (1983, p. 175), Nietzsche "platoniza mais do que em qualquer outro livro" 43 . Partindo de uma visão sobre as diferenças entre os humanos, Platão concluiu que nem todos serão "filósofos" e estes precisariam oferecer dois tipos de ensinamento no mesmo texto, um esotérico, destinado aos leitores de vocação filosófica e marcado pela busca zetética da verdade, outro exotérico, endereçado aos cidadãos e constituído por "nobres mentiras" ou belos mitos úteis para a vida em sociedade ${ }^{44}$. Para Strauss e para Lampert (1996), Nietzsche conhecia essa estratégia esotérica dos filósofos pré-iluministas e reconhecia sua necessidade ${ }^{45}$, mas muitas vezes não conseguia conter o seu próprio coração e continuava escrevendo de forma aberta. Para os teóricos agonísticos, entretanto, este problema sequer existe. Ao contrário do filósofo que os

42 "Onde se encontra a Árvore do Conhecimento, ali é o Paraíso: assim falam as mais antigas e as mais novas serpentes" - Cf. BM, §I 52 (NIETZSCHE, 2005a).

43 Sobre o "platonismo político" de Nietzsche ver também: Tongeren, 2012, p. 257-298 e Lampert, 1996.

44 Ver as seguintes passagens de $A$ República, de Platão (200 I): 377c-e; 379a-b; 388 c; 389b-c; 395 c-d; 459d.

45 Ver, por exemplo, NIETZSCHE BM $\S 28$, $\$ 29$ e $\S 30$ (NIETZSCHE, 2005a); Cl, Melhoradores $\S 5$ e $\mathrm{Cl}$, O que devo aos antigos, §2 (NIETZSCHE, 20I0); VP §428 (NIETZSCHE, 2008); 
inspira, parecem considerar que a busca da verdade e o grau de liberdade e desprendimento dos espíritos livres e filósofos não oferecem riscos e podem ser universalizados. Os teóricos agonísticos, ao pensarem assim, não poderiam estar sendo apenas humanos, demasiado humanos, que querem universalizar o seu próprio modo de vida de homens teóricos? Afinal, a ideia de "respeito agonístico" pressupóe a desconstrução como desejável para todos, como remédio para o fundamentalismo e para o sofrimento causado por padróes sociais. Concordamos que seria positivo para a democracia se mais pessoas sentissem e agissem de acordo com o "respeito agonístico" - se elas puderem fazê-lo sem colher niilismo e anomia junto com a desconstrução dos seus próprios fundamentos morais e políticos. Não negamos que este ethos agonístico mereça a ser estimulado, mas sobrevalorizar essa aposta normativa que requer autolimitação dos sujeitos e negligenciar a dimensão institucional da democracia nos parece um empreendimento pouco realista. Além disso, a desconstruçáo alardeada pelos teóricos agonísticos é apenas parcial, pois aspectos centrais da moralidade moderna criticada por Nietzsche permanecem não examinados na obra destes teóricos, por exemplo, o desejo "louco" de "abolir o sofrimento" (NIETZSCHE, 2005a ${ }^{46}$. Além de desaparecerem questôes difíceis, mas relevantes, como a dimensão cultural e política da "verdade como problema”. Enfim, nas leituras agonísticas e democratas radicais de Nietzsche, perde-se muito do caráter trágico e realista da sua reflexão, atenta como era aos aspectos ambíguos, paradoxais e problemáticos de questóes fundamentais da existência. A teoria democrática contemporânea ganharia mais, e poderia se tornar mais robusta, se procurasse responder, sem afetação dogmática, às críticas que Nietzsche endereçou à nossa moralidade.

\section{Referências}

ACAMPORA, C. D. Demos Agonistes Redux: Reflections on the Streit of Political Agonism. Nietzsche-Studien, v. 32 p. 373-389, 2003.

ACAMPORA, C. D. As Disputas de Nietzsche. Florianópolis: EdUFSC, 2018.

AFARY, J.; ANDERSON, K. (ed.). Foucault e a Revoluçáo Iraniana. São Paulo: É Realizaçôes, 2011.

46 Cf. BM, $\$ 225$. 
APPEL, A. Nietzsche contra Democracy. Ithaca: Cornell University Press, 1999.

BEINER, R. Foucault's Hyper-Liberalism. Critical Review, v. 9, p. 349-70, 1995.

BROBJER, T. Nietzsche's Ethics of Character: A Study of Nietzsche's Ethics and its Place in the History of Moral Thinking. Uppsala: Uppsala University, 1995.

CONNOLLY, W. E. Political Theory and Modernity. Oxford: Blackwell, 1988.

CONNOLLY, W. E. Identity/Difference. Ithaca: Cornell University Press, 1991.

CONNOLLY, W. E. The Ethos of Pluralization. Minneapolis: University of Minnesota Press, 1995.

CONNOLLY, W. E. Why I am Not a Secularist. Minneapolis: University of Minnesota Press, 1999 .

CONNOLLY, W. E. The nobility of democracy. In: FRANK, J. A.; TAMBORNINO, J. (org.). Vocations of Political Theory. Minneapolis: University of Minnesota Press, 2000, pp. 305-326.

CONNOLLY, W. E. Pluralism. Durham: Duke University Press, 2005.

DELBÓ, A. Nietzsche: sobre alguns problemas morais da democracia moderna. Cad. Nietzsche [online], São Paulo, n. 32, p.149-166, 2013.

DELEUZE, G. Mil Platôs. Vol. 1. São Paulo: Editora 34, 1995.

DELEUZE, G. Nietzsche e a Filosofia. Porto: Res Editora, 2001.

DETWILER, B. Nietzsche and the Politic of Aristocratic Radicalism. Chicago: The University of Chicago Press, 1990.

DOMBOWSKY, D. Nietzsche's Machiavellian politics. New York: Palgrave MacMillan, 2004.

FOUCAULT, M. Power/Knowledge. Selected Interviews and Other Writings 1972-1977. New York: Pantheon Books, 1980.

FOUCAULT, M. As palavras e as coisas: uma arqueologia das ciências humanas. São Paulo: Martins Fontes, 2002.

FOUCAULT, M. Ditos e Escritos IV. Estratégia Poder-Saber. Rio de Janeiro: Forense Universitária, 2010.

FOUCAULT, M. Microfísica do poder. São Paulo: Graal, 2012.

HATAB, L. A Nietzschean Defense of Democracy: An Experiment in Postmodern Politics. Illinois: Open Court, 1995.

HATAB, L. Prospects for a Democratic Agon: Why We Can Still Be Nietzscheans. The Journal of Nietzsche Studies, New York, Issue 24, p. 132-147, fall 2002.

KAMRADT, J. Nietzsche, o perfeccionismo e a democracia: tensôes entre Rawls, Cavell e os agonistas. Cad. Nietzsche [online], São Paulo, v. 38, n. 3, p. 207-235, 2017. 
LAMPERT, L. Leo Strauss and Nietzsche. Chicago: University of Chicago Press, 1996.

LEITER, B. Nietzsche on Morality. London: Routledge, 2002.

LOPES, R. Há espaço para uma concepção não moral da normatividade prática em Nietzsche? Notas sobre um debate em andamento. Cadernos Nietzsche, São Paulo, n. 33, p. 89-134, 2013.

MARTON, S. Voltas e reviravoltas acerca da recepção de Nietzsche na França. In: MARTON, S. Nietzsche, um "francês" entre franceses. São Paulo: Ed. Barcarolla; Discurso editorial, 2009. p. 13-52.

MARTON, S. Nietzsche e a crítica da democracia. Dissertatio, Pelotas, v. 33, p. 17-33, inverno de 2011.

MATTOS, F. C. Nietzsche, perspectivismo e democracia: um espírito livre em guerra contra o dogmatismo. São Paulo: Saraiva, 2013.

MOUFFE, C. El retorno de lo político. Barcelona: Paidos, 1999.

MOUfFE, C. Por um modelo agonístico de democracia. Revista de Sociologia e Política, Curitiba, n. 25, p. 11-23, nov. 2005.

MOUFFE, C. En torno a lo político. Buenos Aires: Fondo de Cultura Económica, 2007.

MOUFFE, C.; LACLAU, E. Hegemony and Socialist Strategy. Towards a Radical Democratic Politics. Second Edition. New York: Verso, 2001.

MÜLLER-LAUTER, W. Nietzsche: sua filosofia dos antagonismos e os antagonismos de sua filosofia. São Paulo: Editora Unifesp, 2009.

NIETZSCHE, F. (DH) A disputa de Homero. In: NIETZSCHE, F. Cinco prefácios para cinco livros náo escritos. Rio de Janeiro: 7 Letras, 2005, pp. 63-82.

NIETZSCHE, F. (Co. Ext. II). Segunda Consideraçáo Intempestiva: da utilidade e desvantagem da história para a vida. Rio de Janeiro: Relume Dumará, 2003.

NIETZSCHE, F. (BM). Além do Bem e do Mal: prelúdio a uma filosofia do futuro. São Paulo: Ed. Companhia das Letras, 2005a.

NIETZSCHE, F. (GC). Gaia Ciência. São Paulo: Ed. Cia das Letras, 2005b.

NIETZSCHE, F. (EH). Ecce Homo. São Paulo: Ed. Cia das Letras, 2008a.

NIETZSCHE, F. (VP). A Vontade de Poder. Rio de Janeiro: Ed. Contraponto, 2008b.

NIETZSCHE, F. (CW). O caso Wagner. Um problema para músicos. Nietzsche contra Wagner. Dossiê de um Psicólogo. São Paulo: Cia das Letras, 2009.

NIETZSCHE, F. (CI). O Crepúsculo dos Ídolos. São Paulo: Cia das Letras, 2010.

NIETZSCHE, F. (Z). Assim Falou Zaratustra. São Paulo: Companhia das Letras, 2011.

PASCHOAL, A. E. Nossas virtudes. Indicaçôes para uma moral do futuro. Cadernos Nietzsche, São Paulo, v. 12, p. 53-69, 2002. 
PINHO, L. C. A presença de Nietzsche na obra de Foucault: mais do que uma afinidade filosófica. Princípios, Natal, v. 16, n. 26, p. 167-187, jul./dez. 2009.

PLATÃO. A República. Lisboa: Fundação Calouste Gulbenkian, 10a Edição, 2001.

RAWLS, J. Justice as Fairness: Political not Metaphysical. Philosophy \& Public Affairs, v. 14, n. 3, p. 223-251, summer 1985.

SCHRIFT, A. Alan D. Nietzsche French Legacy: a genealogy of poststructuralism. New York: Routledge, 1995.

SIEMENS, H. Reassessing Radical Democratic Theory in the Light of Nietzsche's Ontology of Conflict. In: ANSELL-PEARSON, K. (org.). Nietzsche and Political Thought. London: Bloomsbury Academic, 2013, pp. 83-105.

STRAUSS, L. Studies in Platonic Political Philosophy. Chicago: The University of Chicago Press, 1983.

THIELE, L. P. The agony of politics: The Nietzschean Roots of Foucault's Thought. The American Political Science Review, Cambridge, v. 84, n. 3, p. 907-925, 1990.

TONGEREN, P. V. A moral da crítica de Nietzsche à moral: estudo sobre Para Além do Bem e do Mal. Curitiba: Champagnat, 2012.

WENMAN, M. Agonistic democracy: constituent power in the era of globalisation. Cambridge: Cambridge University Press, 2013.

Recebido: $28 / 01 / 2020$

Aceito: $04 / 06 / 2020$ 


\section{Laisser aller and agonistic respect: thoughts on the agonistic appropriations of Nietzsche's philosophy}

\section{Abstract}

In this article we analyze the use that agonistic theorists of democracy have made of Nietzsche's philosophy with a focus on one of their main normative propositions: the idea of "agonistic respect". In the first section we present general characteristics of the appropriation of Nietzsche's philosophy by the agonistic theorists of democracy. In the second section we present what William Connolly and Lawrence Hatab mean by "agonistic respect" and "democratic respect". In the third section we criticize these appropriations of Nietzsche's philosophy using Nietzsche's own texts, pointing out some limits of the notion of agonistic respect and claiming that these theorists use Nietzsche to promote a laisser aller ethics that was severely criticized by him.

Keywords: Nietzsche. Agonism. Democracy. Agonistic Respect. 